\title{
As ações do Núcleo Docente Estruturante no processo de educação permanente dos professores em um curso de graduação em Odontologia
}

\author{
Bárbara Morais Arantes ${ }^{1}$ Vânia Cristina Marcelo², Maria Goretti Queiroz³ ${ }^{3}$ Whaine Morais Arantes Filho ${ }^{4}$ e
} Whaine Arantes de Miranda 5 .

${ }^{1}$ Mestre em Odontologia pela Faculdade de Odontologia da Universidade Federal de Goiás (FO/UFG); Especialista em Saúde da Família Universidade Aberta do Sistema Único de Saúde (SUS); Cirurgiã-dentista FO/UFG. ${ }^{2}$ Doutora em Saúde Pública, Universidade de São Paulo; Mestre em Saúde Pública pela Universidade de São Paulo; Cirurgiã-dentista FO/UFG. Professora Associada da FO/UFG. ${ }^{3}$ Doutora em Educação, Universidade Federal de Goiás; Mestre em Educação Escolar Brasileira, Universidade Federal de Goiás, Cirurgiã-dentista FO/UFG. Professor Adjunto IV da Universidade Federal de Goiás. ${ }^{4}$ Cirurgião-dentista FO/UFG; Especialista em Saúde da Família Universidade Aberta do Sistema Único de Saúde (SUS); Especialista em Implantodontia pela FUNORTE-SOEBRAS. ${ }^{5}$ Biomédico, Pontifícia Universidade Católica de Goiás; Farmacêutico, Universidade Federal de Goiás; Acadêmico do Curso de Medicina do Centro Universitário de Anápolis - UniEVANGÉLICA.

\section{Resumo}

Objetivos: Analisar as ações do Núcleo Docente Estruturante (NDE) da Faculdade de Odontologia da Universidade Federal de Goiás (FO/UFG) e identificar sua na reestruturação da matriz curricular, conhcendo a percepção dos atores envolvidos. Metodologia: Utilizou-se entrevistas narrativas semi-estruturadas gravadas e análise documental, com posterior análise de conteúdo. Foram entrevistados docentes da FO/UFG, membros ou não do NDE. Resultados: Observou-se que o NDE teve papel fundamental na implementação e no acompanhamento da reestruturação da nova matriz curricular da FO/UFG, bem como na educação permanente de docentes. Conclusões: Contudo as entrevistas realizadas indicaram uma necessidade de reformulação das estratégias de ação do NDE e de realizar uma agenda de capacitação permanente de docentes, ampliando as propostas das ações das Semanas Pedagógicas.

Palavras-chave: Educação Continuada; Educação em Odontologia; Docentes.

\section{Introdução}

A realidade do mercado de trabalho odontológico tem se modificado profundamente nas últimas décadas. Há crescente número de oferta de faculdades gerando excesso de profissionais em algumas cidades e distribuição dos cirurgiões dentistas de forma irregular nas regiões brasileiras. Além disso, o Sistema Único de Saúde brasileiro, a partir da implementação da Estratégia Saúde da Família tem se constituido em um grande empregador, abrindo vagas para profissionais que tenham a devida capacitação técnica da área e domínio de conhecimentos, habilidades e competências diferenciadas como, por exemplo, aspectos relativos a planejamento, promoção da saúde gestão e gerência de serviços ${ }^{1}$. Por outro lado, as exigências da população a ser atendida têm sido cada vez maiores, demandando profissionais que tenham total domínio das técnicas odontológicas. Faz-se necessário também que seja um profissional mais humano, com práticas que considerem o indivíduo de forma integral e preparado para se atualizar constantemente.

O conhecimento acadêmico não é um conjunto isolado de informações, mas um conjunto comprometido com uma determinada visão do mundo, que se manifesta no próprio processo de investigação do real $^{2,3}$, assim sendo, na formação acadêmica, o docente mais que passar conhecimentos específicos, deve trabalhar na perspectiva da formação do cidadão, contextualizando técnicas, conhecimentos e habilidades, considerando os indivíduos com ética e sensibilidade. Estas exigências demandam novas posturas e atitudes por parte de docentes, pessoal técnico-administrati- vo e discentes ${ }^{4}$ dos cursos de graduação. Estes novos objetivos de formação profissional foram explicitados a partir da Lei de Diretrizes e Bases e de Diretrizes Curriculares Nacionais que substituiram as antigas grades curriculares $^{5,6}$. De modo geral os docentes da área da saúde, e particularmente os da odontologia, tiveram uma formação extremamente tecnicista e pouco contato com áreas da didática, pedagogia e planejamento.

Para superar essa deficiência, subsidiar as ações docentes, atingir os objetivos das Diretrizes Curriculares Nacionais (DCN) e para implantar um novo currículo do curso de graduação, as Faculdades de Odontologia brasileiras têm criado mecanismos que auxiliam na atualização e aquisição de novas competências. No caso específico da Faculdade de Odontologia da Universidade Federal de Goiás (FO/UFG), foi criada a Comissão de Ensino (CE), posteriormente denominada de Núcleo Docente Estruturante (NDE) .

Este estudo teve por objetivo analisar as ações do NDE da FO/UFG e identificar sua na reestruturação da matriz curricular, conhcendo a percepção dos atores envolvidos.

\section{Metodologia}

A abordagem do presente estudo é qualitativa, a qual preocupa-se com a realidade que não pode ser quantificada e aprofunda-se no mundo do significado das relações humanas 7. O estudo foi realizado após submissão e aprovação pelo Comitê de Ética da Universidade Federal de Goiás (CEP/UFG), protocolo n 011/2009.

Utilizou-se da técnica de entrevistas narrativas semi-estruturadas gravadas e da análise docu- 
mental, com levantamento em portarias, memórias, Projeto Pedagógico do Curso da FO/UFG, Diretrizes Curriculares Nacionais para os cursos de Odontologia $(\mathrm{DCNO})^{5}$ e Projeto do Programa Nacional de Reorientação da Formação Profissional em Saúde - Pró-Saúde. O período considerado para coleta de documentação do NDE foi desde sua implementação, em 26 de março de 2007, até junho de 2010. Foram realizadas entrevistas com o Diretor do curso, membros da Comissão de Ensino e com docentes e pessoal Técnico Administrativo (TA) da FO/UFG selecionados aleatoriamente. A amostra final foi composta de 14 docentes e 06 TA. O número de entrevistas foi finalizado quando as categorias do discurso se repetiram ${ }^{7}$. Os dados foram examinados com análise de conteúdo ${ }^{7,8}$.

\section{Resultados}

Os resultados foram descritos em tópicos, conforme as categorias emergentes.

\section{Ações da Comissão de Ensino}

Para a construção do novo currículo da FO/ UFG foi criada a Comissão de Reestruturação Curricular. Porém tamanha era a importância, abrangência do seu papel e interligação com as demais áreas, que em 26 de março de 2007, por meio da Portaria $n^{\circ} 005 / 2007^{9}$, resolveu-se designar os membros que compuseram a primeira conformação da Comissão de Ensino da $\mathrm{FO} /$ UFG, a qual contou com 08 docentes e 01 TA, e que estava vinculada à Coordenção de Curso, pelo período de 01 de abril de 2007 a março de 2008. Tinha como atribuições elaborar o Projeto Político Pedagógico da FO/UFG; empreender processos de avaliação, de reformulação e alterações necessárias à consolidação do referido projeto; orientar e acompanhar a implementação do novo currículo da FO/UFG.

Em 09 de junho de 2008 a CE passou a ser composta por 12 docentes e 02 TA com as atribuições de concluir o Projeto Pedagógico Curricular (PPC) da FO/UFG; implementar e acompanhar o novo currículo da FO/UFG; dar suporte didático-pedagógico aos Conselhos de Classe da FO/UFG; coordenar os períodos de planejamento pedagógico-administrativo, semestralmente; e outras atividades inerentes à Comissão de Ensino - não especificadas no documento.

A Portaria $n^{\circ}$ 021/2009 10, de 03 de julho de 2009, designou um NDE composta por 13 docentes e 02 TA, a qual concluiu o PPC em 03 de dezembro de 2009. O NDE passou a ter o papel de acompanhar e avaliar o novo currículo além de continuar apoiando as ações pedagógico-administrativas desenvolvidas na faculdade. Em 17 de agosto de 2010, pela Portaria n 016/201011, foi designado uma nova composição e nova denominação à NDE. Desde então passou a se chamar Núcleo Docente Estruturante (NDE). Passando a ser composto por 19 integrantes, entre eles, professores das disciplinas do núcleo básico.

\section{Influência na Educação Permanente dos Docentes}

As memórias de reuniões e resultados de ava- liação docente e de TA sobre as semanas pedagógicas demonstraram, que a participação foi sendo incentivada gradativamente, à medida que um indivíduo conscientizava o outro da necessidade de agir.

$\mathrm{Na}$ memória de uma reunião do NDE (19/11/2009) esse fato foi ilustrado: Ao final foi apresentado o resultado da enquete sobre os temas para a semana pedagógica que aconteceu entre 09 a 11 de fevereiro de 2010. Os temas mais votados foram: o ensino e o estudante da era digital; o "ser professor" frente ao novo currículo; calibração dos professores e TA (assuntos diversos).

Um fator levantado como facilitador da realização de atividades de educação permanente foi a disposição dos docentes em participar das propostas e inclusão de novos docentes. Em contrapartida, teve-se a falta de recursos e a alta carga-horária dos docentes como pontos dificultadores. Não há recursos para fazer essas oficinas, esses encontros, constantemente. Além disso, há as questões burocráticas e a elevada carga horária de ensinagem. Muitos alegam não ter tempo para participar dessas oportunidades de capacitação. (E 2).

\section{Influência na Reestruturação da Nova Matriz Cur- ricular}

A Portaria $n^{\circ}$ 005/2007 9 estabeleceu como função do NDE orientar e acompanhar a implementação do novo currículo da FO/UFG. Diante disso o NDE desempenhou papel fundamental na adaptação do corpo docente e técnico às mudanças curriculares, além de auxiliar na adequação das disciplinas do novo currículo às exigências das DCNO.

Primeiramente o NDE teve forte representatividade junto às disciplinas do ciclo clínico. Realizou-se reuniões com grupos de docentes de cada disciplina, periodicamente, para discutir anseios, métodos de ensino-aprendizagem, relacionamento interpessoal, entre outros assuntos. De modo geral foi reforçada a necessidade de compreensão de que as mudanças deveriam ser conduzidas por todos os professores, que os diferentes conteúdos precisariam ser re-distribuídos em uma nova perspectiva das disciplinas que compõem o novo currículo, a participação dos docentes nas disciplinas e os formatos das aulas e das avaliações precisariam ser re-adequados para atender às novas necessidades.

Em 07 de julho de 2008, durante uma reunião do NDE com as disciplinas de Clínica de Atenção Básica I e II, Prótese Dentária I e II e Estágio em Clínica Integrada I a IV, vizualizou-se que houve avanços nos processos de construção dessas disciplinas, bem como o avanço do corpo docente da FO/UFG quanto aos aspectos pedagógicos requeridos diante da realidade atual do curso. Estes aspectos variaram desde a apresentação de resultados do planejamento interno e as perspectivas para o futuro, até formatos de auto-avaliação, avaliação discente e formas de integração entre teoria e prática e com outras disciplinas. Neste contexto, alguns professores discutiram a necessidade de manter a inter-relação e integração com as disciplinas do ciclo 
básico.

Outra forma de intervenção do NDE na implementação e no acompanhamento do novo currículo foi o apoio aos concursos para novos professores, desenhando o perfil para o preenchimento das vagas e o formato do processo de seleção. A comissão forneceu subsídios desde a elaboração dos editais até a avaliação em si dos concorrentes.

O NDE participou também de discussões de adequação das cargas horárias às demanadas observadas durante o desenvolvimento das atividades do novo currículo. Em 17 de agosto de 2009 os professores evidenciaram a necessidade de aumento do número de horas dedicadas aos conteúdos de endodontia. A redistribuição das horas foi fator defendido junto à Coordenação de Curso. Uma nova estrutura foi elaborada e apresentada ao Conselho Diretor e à NDE, e acatada. estimula a renovação dos conhecimentos. O NDE orientou a construção dos programas de aprendizagem de maneira integrada estimulando os docentes a implementarem as mudanças de conteúdo respondendo às DCNO. Ela tem organizado encontros com especialistas na área pedagógica, o que muito contribui para a formação permanente do docente. (E 10).

\section{Percepção de Docentes e TA da FO/UFG quanto às Atividades Desempenhadas pelo NDE}

Encontrou-se duas visões distintas sobre este tópico. Um grupo com uma imagem positiva e outro com uma imagem negativa. O Quadro 1 retrata as idéias associadas pelos docentes e TA.

Sobre a reorientação das disciplinas, um docente disse: As reuniões com a comissão despertaram em mim uma nova visão de ensino e trabalho em equipe! [...] as reuniões deram oportunidade aos professo-

Quadro 1 - Percepção dos Docentes da FO/UFG sobre as atividades do NDE.

\begin{tabular}{ll}
\hline Aspectos ligados à imagem positiva & \multicolumn{1}{c}{ Aspectos ligados à imagem negativa } \\
\hline Reorientação das disciplinas & $\begin{array}{l}\text { Pouca carga horária de atividades junto } \\
\text { aos docentes e TA durante } 0 \text { ano }\end{array}$ \\
Semanas pedagógicas e administrativas & $\begin{array}{l}\text { Poucas atividades de motivação do } \\
\text { docente para participar do processo de } \\
\text { mudanças }\end{array}$ \\
Reuniões periódicas com disciplinas & $\begin{array}{l}\text { Falta de um boletim de divulgação das } \\
\text { atividades do NDE }\end{array}$ \\
Integração dos ciclos básico e clinico & Pouca objetividade \\
\hline
\end{tabular}

Percepção de Membros do NDE da FO/UFG quanto ao seu Papel na Educação Permanente dos Docentes da Faculdade

Os relatos obtidos nas entrevistas com membros do NDE apresentaram-se homogêneos quanto à percepção de seu papel na educação permanente de docentes da faculdade. As perguntas iniciavam-se com: Qual o papel da Comissão de Ensino (CE) na educação permanente dos docentes e técnicos da FO/UFG no que se refere às práticas docentes, à construção dos programas de aprendizagem das disciplinas e no relacionamento inter-pessoal?

Os docentes e TA entrevistados expuseram o que pensavam e sentiam em relação ao tema: as práticas desempenhadas pelos professores sofrem influência dos avanços que existem no nosso currículo. E isso é repassado aos docentes via Comissão de Ensino! Ela tem um programa de capacitação docente, que periodicamente promove reuniões, para deixar os docentes atualizados, para colocá-los a par dos acontecimentos na área de ensino-aprendizagem e assim por diante. Então é um papel muito importante, mesmo porque se estimula a participação dos TA nessas reuniões, oficinas e seminários! (E 7).

Outro membro disse: o papel do NDE é de vital importância pois nos faz revisar nossas práticas e res de ajustarem os conteúdos com a necessidade prática! (E 16).

Apesar deste relato, o mesmo docente disse: $A$ comissão deve tratar mais especificamente dos assuntos que propõe! De maneira mais direta, mais prática e objetiva. (E 16).

As ações do NDE envolvendo TA eram consideradas, por estes, poucas até o início de 2010. Desde então as atividades se intensificaram. Teve-se em um depoimento: A comissão começou realizando umas atividades com a gente durante as semanas pedagógicas, mas depois parou. Neste período de parada teve reunião com a direção por causa da mudança administrativa, mas nada com o NDE. [...] com a regulação a comissão realizou a calibração e muitas reuniões para a gente ficar por dentro das mudanças na faculdade. (E 18).

Outro TA ressaltou: Desde o começo do ano [2010] a gente está tendo a maior atenção deles [NDE], mesmo assim acho que os técnicos são um pouco esquecidos. Acho que poderia ter mais momentos. Depois que começou a mudar tudo, o currículo, os cargos, a gente ficou meio perdido e precisa de atenção, até para motivar a gente. Sinto falta! (E 09)

Um entrevistado ressaltou, como ponto positivo, as reuniões de integração entre o corpo docente 
e técnico. Disse: me lembro que no finalzinho de 2008, houve uma reunião com todos os professores e técnicos, para assistirmos ao vídeo que fizeram da faculdade. [...] essa foi uma oportunidade de confraternização muito boa. Isso poderia ocorrer mais frequentemente! (E 11).

\section{Fatores que Determinam o Desenvolvimento ou não de Práticas Metodológicas Ativas de Ensino-Apren- dizagem}

Um dos objetivos específicos do PPC da FO/ UFG foi "Priorizar os processos de ensino-aprendizagem que utilizem metodologias ativas"12. Isso foi passado aos docentes pelo NDE durante as semanas pedagógicas, oficinas e momentos de calibração. Quando perguntados sobre os fatores que determinam ou não a adoção de metodologias ativas, os docentes foram diretos: A própria formação dos docentes da FO/UFG.

Isto se evidenciou no seguinte depoimento: $O$ corpo docente, na sua maioria absoluta, tem uma formação muito tradicional, baseada no modelo hospitalocêntrico, que teve reflexos na odontologia [...] para o professor que foi formado dessa maneira, trazer inovações ou metodologias novas, é culturalmente difícil, ou seja tem que mudar a cultura do professor. E isso tem acontecido à medida que o professor também procura se desenvolver como pessoa e como profissional. (E 03).

O discurso de um docente foi: Todos nós nos atualizamos. Agora isso não caminha de uma forma mágica. Não há como você ter ontem um currículo tradicional e hoje um currículo moderno, cheio de metodologias ativas. Esse é um processo que demanda tempo, porque demanda conscientização, mudança de postura na sala de aula. (E 04)

Outro professor relatou: As maiores dificuldades são o nosso despreparo quanto às técnicas ativas de ensino-aprendizagem e a nossa formação tradicional. Nós não temos formação pedagógica. [...] algumas pessoas procuram mais do que outras por essa formação, lendo um pouco. A própria prática ajuda a gente a melhorar, à medida que a gente vai executando a gente avalia 'ah isso deu certo, isso não deu certo'. (E 08).

Um docente em seu depoimento lembrou que: NDE tem contribuído durante as semanas pedagógicas trazendo pessoas que entendem do assunto fazendo com que a gente tenha subsídio para melhorar as técnicas de ensino-aprendizagem. Deixando de ser apenas um profissional técnico dando aula e sim ser realmente um docente, com formação docente. (E 19).

\section{Discussão}

A formação de comissões com funções pedagógicas tem sido uma tônica em todo o país, desde 0 ensino fundamental até o superior ${ }^{12-16}$.

Muitos nomes são adotados para designar essas comissões, como por exemplo: Comissão de Ensino, Comissão Pedagógica e Núcleo Docente Estruturante (NDE). Este último aparecendo em documentos do Ministério da Educação. Segundo Flores Filho e Oliveira (2009) ${ }^{16}$ o NDE constou na Portaria n ${ }^{\circ} 147 / 2007^{13}$, num momento de transição entre o Decreto n 3.860/2001 e o Decreto $n^{\circ} 5.773 / 2006$, que dispõem sobre organização e avaliação de instituições de ensino superior ${ }^{17,18}$. De acordo com a portaria, o NDE seria responsável pela formulação do PPC de cada instiuição, sua implementação e desenvolvimento.

As comissões de avaliação do Instituto Nacional de Pesquisas Educacionais (INEP) têm exigido um núcleo de docentes caracterizado como uma estrutura administrativo-pedagógica criada a partir de regras internas das próprias instituições de ensino. Portanto as atribuições previstas na Portaria $n^{\circ} 147 / 2007^{13}$, poderiam ser extrapoladas a medida que a instituições jugassem necessário e benéfico. Neste contexto o NDE da FO/UFG foi criada em 2007, com as funções originais descritas na referida portaria e outras adequadas à realidade da instituição. Tudo com intúito de suprir uma deficiência existente há muito tempo na faculdade: a formação tecnicista do docente. O NDE se propôs a subsidiar os processos formativos na referida faculdade, criando momentos para realização de educação permanente, reflexão do "ser professor", além do fortalecimento do sentimento de unidade e responsabilidade com o processo de mudança.

Dentre as ações levantadas neste estudo, destacam-se a construção participativa do PPC, o apoio ao planejamento das novas disciplinas e a realização das Semanas de Planejamento Administrativo e Pedagógico no início de cada semestre letivo, cumprindo o objetivo de elaborar e proporcionar momentos de reflexão e de comprometimento com a melhoria do modo de ensinar e de aprender, prática que vem sendo realizada em outras instituições de ensino em todo o País com diversas variações de forma e conteúdo ${ }^{19}$. Outros temas trabalhados foram realidade do ensino em saúde, aspectos administrativos do curso, enfrentamentos e realizações do cotidiano de uma ou outra fração da faculdade (departamentos, disciplinas, etc.).

Apesar da carga horária dos membros do NDE ser considerada exaustiva por eles mesmos, muitos dos docentes e TA entrevistados alegaram que desejariam ter mais oportunidades de capacitação e treinamento. Ressaltaram que o NDE está muito presente no início de cada semestre, porém pouco durante seu desenrolar.

A não participação de alguns docentes no NDE poderia explicar este contraste de opiniões. Por exemlo: um determinado docente é membro do NDE. Ele vivencia todos os fatos e acontecimentos durante os semestres. Portanto considera que a carga horária é alta. Em contrapartida tem-se um professor que só participa da semanas de planejamento pedagógico, sem se envolver no processo de mudança. Este professor, não está errado em considerar que o NDE pouco faz na faculdade, afinal ele não se envolveu a ponto de identificar mais momentos.

Isto não significa que os professores, que se manifestaram a favor da realização de mais atividades, estejam equivocados. Muitos destes disseram claramente tentar se envolver, procurar se atualizar na lite- 
ratura, mas sentem a falta do subsídio do NDE neste processo de mudança postural.

Entendendo que a capacitação dos docentes é fator fundamental para implementação da Nova Matriz Curricular, fica clara a necessidade de uma reformulação das estratégias de ação do NDE e de realizar uma agenda de capacitação permanente de docentes e TA. Os pontos básicos desta agenda deveriam ser a sensibilização sobre os processos de mudança e a discussão sobre metodologias ativas de aprendizagem, avaliação formativa, informatização dos processos de trabalho, inter-relação ensino/serviço/comunidade e integração ensino/pesquisa/extensão.

O NDE influenciou a adequação das disciplinas do novo currículo à realidade da FO/UFG. Inclusive estimulando a adoção de metodologias ativas de ensino-aprendizagem, onde o professor não configuraria como única fonte de saber. Apesar do esforço constante do NDE de inserir essas novas metodologias nos planos de aprendizagem e de capacitar os docentes para tal, ainda há uma insegurança destes no dia a dia da docência.

Percebeu-se a necessidade de calibração de conceitos e linguagens (terminologia), o que poderia ser alcançado por meio do planejamento interdisciplinar, do diálogo entre as áreas de atuação em odontologia. Pois apesar de o currículo ter a proposta de integração, observa-se uma dificuldade de se trabalhar os conteúdos de forma integrada.

Assim foram criados instrumentos para que os professores que não se sentem comprometidos, passem a ver seu papel como formadores de profissionais críticos e reflexivos.

\section{Conclusões}

Os NDE teve papel fundamental na implementação e no acompanhamento da reestruturação curricular dos cursos de graduação em Odontologia bem como na educação permanente de docentes e TA. Inclusive revisando constantemente os PPC. Os professores reconheceram que as ações dos NDE são válidas dentro de um contexto histórico e no processo de mudança curricular. Porém consideraram que o NDE deveria realizar mais atividades de capacitação do corpo docente e técnico, visando uma adequação à realidade, que consiste em quadro de professores com formação tradicional, sem a formação pedagógica adequada.

Espera-se que os resultados deste estudo possam fundamentar o planejamento de cursos de capacitação e qualificação de recursos humanos para adequação das matrizes curriculares às reais necessidades de formação do profissional cirurgião-dentista na dinamicidade do Brasil contemporâneo.

\section{Referências}

1. Pinto VG. Saúde Bucal Coletiva. $4^{a}$ Ed. São Paulo: Editora Santos. 2000.

2. Leite SB. Considerações em torno do significado do conhe- cimento. In: Moreira AFB. Conhecimento educacional e formação do professor - Questões atuais. 4 ed. Campinas: Papirus; 2001. p. 11-25.

3. Chaves SM. A aprendizagem do estudante universitário em saúde: descortinando práticas, buscando alternativas. In: Estrela C. Metodologia Científica - Ciência. Ensino. Pesquisa. São Paulo: Artes Médicas; 2005. p. 741-748.

4. Ministério da Saúde. Política Nacional de Educação Permanente em Saúde. Portaria No 198/GM/MS. Diário Oficial da União. n 32/2004, seção I- Brasília. Brasil (13 de fevereiro de 2004).

5. Conselho Nacional de Educação. Câmara de Educação Superior. Institui Diretrizes Curriculares Nacionais do Curso de Graduação em Odontologia. Resolução Nº CNE/CES 3, de 19 de fevereiro de 2002. Diário Oficial da União, Brasília, Seção 1- p10. Brasil. (04 de março de 2002).

6. Mattos D. As novas Diretrizes Curriculares e a Integralidade em Saúde: Uma análise das possíveis contribuições da Odontologia para o trabalho em equipe [Dissertação de Mestrado] Rio de Janeiro: Universidade Estadual do Rio de Janeiro. Instituto de Medicina Social; 2006.

7. Minayo MCS. O desafio do conhecimento: pesquisa qualitativa em saúde. $4^{a}$ ed. São Paulo: Hucitec; 1992.

8. Bardin, L. Análise de conteúdo. Portugal: Edições; 1977.70 p. 9. Universidade Federal de Goiás. Faculdade de Odontologia. Secretaria do Curso de Odontologia. Portaria $n^{\circ}$ 005/2007. Goiânia, GO (26 de março de 2007).

10. Universidade Federal de Goiás. Faculdade de Odontologia. Secretaria do Curso de Odontologia. Portaria n $021 / 2009$. Goiânia, GO (03 de julho de 2009).

11. Universidade Federal de Goiás. Faculdade de Odontologia. Secretaria do Curso de Odontologia. Portaria n 016/2010. Goiânia, GO (17 de agosto de 2010).

12. Universidade Federal de Goiás. Faculdade de Odontologia. Projeto Pedagógico do Curso de Odontologia (PPC-FO/UFG). Goiânia (novembro de 2009).

13. Brasil. Ministério da Educação. Portaria n 147/2007, 02 de fevereiro de 2007. Dispõe sobre a complementação da instrução dos pedidos de autorização de cursos de graduação em Direito e Medicina. Diário Oficial da União. Brasilia, DF (05 de fevereiro de 2007).

14. Carabetta Junior V; Cury MCFS. A Contribuição da Coordenação Pedagógica na Escola de Medicina. Rev. Bras de Educação Médica; 2007. 31 (1): 44-51.

15. Escola Franciscana Nossa Senhora de Fátima [Internet]. Coordenação Pedagógica do Ensino Fundamental do $6^{\circ}$ ao $9^{\circ}$ ano. 2009 [citado 2009 outubro 07]. Disponível em: http: // www. escolafatima. g12. br/escola/arquivos /coord_pedag_ fund_6_9.

16. Flores Filho EGJ; Oliveira JA. Núcleo docente estruturante pode ser exigido das IES? [Internet]. Publicação no site Gestão Universitária; 2009 [atualizado 2009 julho 08; citado 2009 ou- 
tubro 07]. Disponível em: http: // www. gestaouniversitaria.com. br / edicoes/177-196/21234--o-nucleo-docente-estruturante-pode-ser-exigido-das-ies-html.

17. Brasil. Decreto - Lei $n^{\circ} 3.860$, de 09 de julho de 2001. Dispõe sobre a organização do ensino superior, a avaliação de cursos e instituiç̧̃̃es, e dá outras providências. Diário Oficial da União. Brasília, DF (10 julho de 2001).

18. Brasil. Decreto - Lei $n^{\circ} 5.773,09$ de maio de 2006. Dispõe sobre o exercício das funções de regulação, supervisão e avaliação de instituições de educação superior e cursos superiores de graduação e seqüenciais no sistema federal de ensino. Diário Oficial da União. Brasilia, DF (10 de maio de 2006).

19. Guimaraes EMP; David HMSL. Iniciativa de Educação Permanente em Enfermagem - IEPE [Internet]; 2004 [Citado 2009 dezembro 15]. Disponível em: www.abennacional.org.br/IEPE/

Recebido em : 20/05/2017

Aprovado em: 21/06/2017

Os autores declaram que não há conflitos de interesse.

\section{Autor correspondente:}

Bárbara Morais Arantes

Rua Comendador Negrão de Lima, n 151, Edifício Lago

Azul, apartamento 402 A, CEP 74650030, Goiânia GO

barbaraufg@yahoo.com.br 


\title{
The actions of the Structuring Teaching Nucleus in the process of permanent education of the professors in a dentistry school
}

\begin{abstract}
Objectives: This research aims to analyze the actions of Structuring Teaching Nucleus of the under graduation course of dentistry in the Federal University of Goias (FO/UFG) and identify its influence in the reorganization of the new curricular matrix, knowing the perception of the involved actors. Methodology: For that purpose were used semi-structured recorded narrative interviews and documentary analysis, with later content analysis. Professors of the FO/UFG, members or not of the Structuring Teaching Nucleus were interviewed. Results: It was observed that the Structuring Teaching Nucleus played a fundamental paper in the implementation and the follow-up of the reorganization of the new curricular matrix of the FO/UFG, as well as in the permanent education of professors. Conclusions: However the carried through interviews indicated a necessity of rebuilding the strategies of action of the Structuring Teaching Nucleus and to carry through an agenda of permanent qualification of professors, enlarging the proposals of the Pedagogical Weeks.
\end{abstract}

Keywords: Continuing education; Dental Education; Odontology. 